Int. J. Electrochem. Sci., 16 (2021) Article ID: 210514

International Journal of

ELECTROCHEMICAL

SCIENCE

$\underline{\text { www.electrochemsci.org }}$

\title{
Development of Semitransparent UV Photodetector Based on PTB7-Th:PCBM Composite Using the Cost-effective Fabrication Method
}

\author{
Muhammad Riaz, Muhammad Mehran Bashir ${ }^{2}$, Khasan S. Karimov $^{2}$, Jameel-Un Nabi ${ }^{3}$, \\ Rana Tariq Mehmood Ahmad ${ }^{4}$, Zubair Ahmad ${ }^{5, *}$, Atif Mehmood ${ }^{6}$ \\ ${ }^{1}$ Department of Physics, University of Okara, Okara, Punjab, 56300, Pakistan. \\ ${ }^{2}$ Ghulam Ishaq Khan Institute of Engineering Sciences and Technology, Topi, District Swabi, KPK, \\ 23640, Pakistan. \\ ${ }^{3}$ University of Wah, Quaid Avenue, Wah Cantt 47040, Punjab, Pakistan \\ ${ }^{4}$ Department of Electrical Engineering, Narowal Campus, University of Engineering \& Technology, \\ Lahore, 54890, Pakistan. \\ ${ }^{5}$ Qatar University Young Scientists Center (YSC), Qatar University, 2713, Doha, Qatar \\ ${ }^{6}$ Department of Electrical and Computer Engineering, Sahiwal Campus, COMSATS University \\ Islamabad, 57000, Pakistan. \\ *E-mail: zubairtarar@qu.edu.qa
}

doi: $10.20964 / 2021.05 .12$

Received: 4 January 2021 / Accepted: 24 February 2021/ Published: 31 March 2021

This article presents a semitransparent ultraviolet (UV) sandwich-surface type sensor based on PTB7Th: PCBM composite. The ultraviolet (UV) transparency of $29 \%$ was achieved through a cost-effective drop-cast fabrication method. The variation in UV intensity ( 0 to $20,000 \mu \mathrm{W} / \mathrm{cm}^{2}$ ) and frequency $(100$ $\mathrm{Hz}, 1 \mathrm{kHz}, 10 \mathrm{kHz}, 100 \mathrm{kHz}$, and $200 \mathrm{kHz}$ ) was carried out, and variation of impedance and capacitance has been studied. After a comprehensive analysis under specific UV strength and frequency, a considerable increase in capacitance and a significant decrease in impedance were observed. The generation of electron-hole pair relates such findings by increasing the concentration of charges, combined potential, and possible frequency dependence of charge mobility under UV-irradiation. The UV sensor can be used for measuring the UV and visible light intensities. They have applications in the field of electronics and photonics.

Keywords: UV sensor, PTB7-Th: PCBM, semitransparent, sandwich-surface type sensor

\section{FULL TEXT}


(C) 2021 The Authors. Published by ESG (www.electrochemsci.org). This article is an open access article distributed under the terms and conditions of the Creative Commons Attribution license (http://creativecommons.org/licenses/by/4.0/). 